\title{
Experimental Acute Sepsis Reduced Number of Osteocalcin Immunolabeled Cells in Periodontal Ligament
}

Gabriela Veloso Vieira da Silva Pinheiro ${ }^{1}$, Robinson Sabino-Silva ${ }^{2}{ }^{\circ}$, Melissa Rodrigues de Araujo ${ }^{3}{ }^{\oplus}$, Shaiene Patrícia Gomes ${ }^{4}{ }^{\circ}$, Stephanie Wutke Oliveira $^{2} \odot$ Emilia Maria Gomes Aguiar ${ }^{2} \oplus$, Léia Cardoso-Sousa ${ }^{2} \oplus$, Carla Castiglia Gonzaga ${ }^{4} \oplus$, Marcela Claudino ${ }^{1}{ }^{\circledR}$
'UEPG - Universidade Estadual de Ponta Grossa, Ponta Grossa, PR, Brazil ${ }^{2}$ Department of Physiology, Institute of Biomedical Sciences, UFU - Universidade Federal de Uberlândia, Uberlandia, MG, Brazil 3UFPR - Universidade Federal do Paraná, Curitiba, PR, Brazil ${ }^{4} \mathrm{UP}$ - Universidade Positivo, Curitiba, PR, Brazil

Correspondence: Marcela Claudino, Rua Carlos Cavalcanti 4748, 84030900 Ponta Grossa, PR, Brasil. Tel: +55-42-99813-0395. e-mail: marcelaclaudino@hotmail.com \& Robinson Sabino-Silva, Institute of Biomedical Sciences (ICBIM-UFU), Av. Pará, 1720, Campus Umuruama, 38400-902, Uberlândia, MG, Brasil. Tel: +55-34-3218-2100. e-mail: robinsonsabino@gmail.com

Key Words: sepsis, osteocalcin, periodontium.

\section{Introduction}

Sepsis is a dysregulated pathophysiologic immune response to infection resulting in severe organ dysfunction. A recent meta-analysis estimates incidence of 31 million sepsis cases with 6 million deaths per year. However, the accurate values are probably even greater. The World Health Organization indicated sepsis as a global health priority. The septic inflammatory response in the body is complicated by secondary end organ damage. In particular, cardiovascular and pulmonary changes leading to tissue hypoperfusion, which has clinical relevance in therapeutic approach of sepsis (1-3). Sepsis is fundamentally an inflammatory disease mediated by the host immune response. In this context, this condition result in dysregulated hyperinflammation that can lead to the many symptoms including disseminated intravascular coagulation and subsequent multi-organ dysfunction syndrome, inflammation-coagulation due to aberrant platelet activation, peripheral vasodilation leading to low blood pressure ensuing hypoperfusion of the kidney and kidney failure (4). In fact, altered levels of inflammatory mediators may be observed in septic patients (5). Higher levels of proinflammatory mediators were shown in patients who died than in survivors, suggesting an association of high levels of these mediators and sepsis outcome (6).

Indeed, it is possible that sepsis exerts a relevant influence on different biological systems (7-8) and these effects are possibly due to dysregulation of the immune and inflammatory response after induction and establishment of sepsis. In this context, the periodontium can also be affected by sepsis deregulation. Previous studies have been demonstrated that systemic diseases can modulate the immune and inflammatory responses which can develop injury in periodontal tissues, even in the absence of induction of periodontal disease (9-12).

In this modulation, increased levels of proinflammatory cytokines can exert influence in several systems. This increase may result in elevated levels of RANKL, known to be involved in the osteoclastogenesis process (13). Since a balance between deposition and tissue resorption regulates bone metabolism, changes in morphogenetic bone protein levels, such as BMP-2/4, may also affect the osteogenic process (14). This scenario directly involves the functioning of osteoblasts and osteocytes, which synthesize osteocalcin, the most abundant non-collagenous bone matrix protein involved in the mineralization process (15). A dental 
infection can lead to sepsis. Recently, acute inflammation, as a consequence of sepsis induction, was related with bone loss by osteoblast ablation (16).

Thus, it is possible to observe that sepsis seems to interfere in different systems. However, the influence of acute sepsis on the periodontium, in absence of periodontal diseases, remains unknown. In addition, the evaluation of these possible effects is commonly performed over longer periods (4-6). However, a previous study reported histological and molecular changes in the lung after $24 \mathrm{~h}$ of sepsis induction (7). In this way, it would be interesting to evaluate the effects of shorter-term sepsis induction on the periodontal microenvironment. Therefore, the aim of this study was to evaluate the putative effect of acute sepsis in the periodontal ligament, alveolar and furcation bone in absence of periodontitis induction through histological and immunohistochemical analyses.

\section{Material and Methods}

The experimental project was approved by the Ethics Committee for Animal Research of the Federal University of Uberlandia, protocol \#45/2015. All experiments were
CLP was induced by a sublethal polymicrobial sepsis. The CLP procedure occurs in rats under anesthesia with ketamine $(90 \mathrm{mg} / \mathrm{kg})$ and xylasine $(10 \mathrm{mg} / \mathrm{kg})$, intraperitoneally. After that, an aseptic midline laparotomy was made to exteriorize a portion of cecum. A partial ligation of cecum was made using a 4.0 silk tie, followed by nine times perforation with a 22-gauge needle. Cecum was also gently squeezed to remove a small amount of feces from perforation. After that, the portion of cecum was reinserted into abdominal cavity and the laparotomy was sutured using a 4.0 silk sutures. Sham animals received the same procedure by the same operator; however, the cecum was not perforated (9). Body temperature of animals was maintained at $37.5 \pm 1.5^{\circ} \mathrm{C}$ with a heating blanket during experimental procedures. All rats were under free access to water and standard rodent chow diet (Nuvilab CR-1; Nuvital, Curitiba, Brazil). Both Sham and CLP rats were studied $24 \mathrm{~h}$ after sepsis induction. After euthanasia, the mandibles were removed using dissection and divided into two hemimandibles. This procedure was carried out under absence of corneal palpebral reflex and the reflex of paw retrieval upon digital pinching were ensured.

\section{Histological and Immunohistochemical Analyses}

The hemimandibles were fixed in 10\% formalin solution at 10\% for $48 \mathrm{~h}$ and descalcified for 8 weeks in 18\% EDTA., washed, dehydrated and embedded in paraffin. Serial sections ( 5 semi- serial sections of each hemimandible) with $5 \mathrm{~mm}$ thickness were cut and stained with haematoxilin and eosin. In the sequence, all histological sections were identified with a random numerical sequence in order to codify experimental periods and groups during the analysis procedures, and the $1 \mathrm{st}, 3 \mathrm{rd}$, and 5 th were analyzed by a single calibrated investigator with a binocular microscope (Olympus BX41, Tokyo, Japan).

For the furcation region and the alveolar bone analysis, five fields were chosen, as illustrated in Figure $1 \mathrm{~A}$ and $1 \mathrm{~B}$. Moreover, 15 histological fields per histological section were evaluated, comprising all the periodontal area, from the junctional epithelium to the root apex of mesial face of lower first molar mesial root (Fig. 1C). These images were captured using the platform Olympus CellSens (CellSens Software 1.6, Tokyo, Japan).

The criteria evaluated in the morphometric analysis were: bone matrix, collagenous fibers, fibroblasts, osteocytes, inflammatory cells, blood vessels and other components of conjunctive tissue (inflammatory exudate, intercellular liquid and amorphous fundamental substance).

The immunohistochemical analysis was performed using the streptavidin-biotin-peroxidase method. Paraffin sections (3 semi-serial section of each animal) were deparaffinized with xylol, dehydrated in decreasing alcohol solutions, and the endogenous peroxidase was blocked with
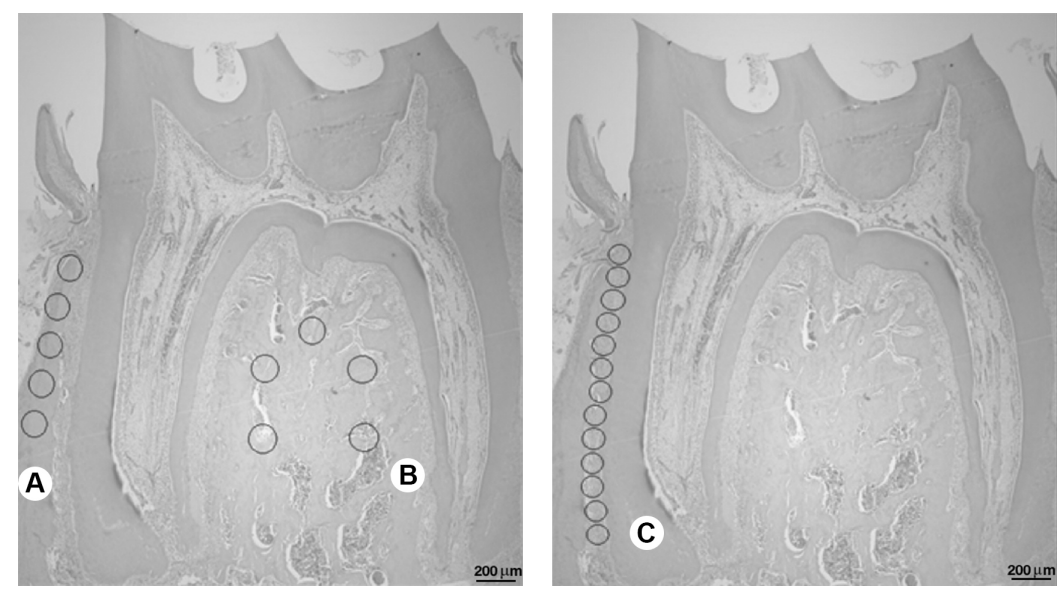

Figure 1. Schematic distribution of histological fields in alveolar bone (A), furcation region (B) and periodontal ligament (C). 
EnVision TM FLEX for $10 \mathrm{~min}$ at room temperature, then washed again three times in the EnVision TM FLEX Wash buffer (Dako, Glostrup, Denmark). For antigen retrieval, sections were treated with pre-heated EnVision TM FLEX Target retrieval solution (Low pH, Dako) and incubated for 20 min at $97^{\circ} \mathrm{C}$ using a microwave.

Specific primary antibodies for RANKL (sc-7628-Santa Cruz Biotechnology, Inc., Santa Cruz, CA, USA) at 1:50 dilution; osteocalcin (sc-365797-Santa Cruz Biotechnology, Inc.), at 1:50 dilution; and BMP-2/4 (sc-137087-Santa Cruz Biotechnology, Inc.), at 1:50 dilution were applied and incubated for $20 \mathrm{~min}$ at room temperature in a humidified chamber.

After washing, the sections were incubated with EnVision FLEX/HRP for $20 \mathrm{~min}$ at room temperature followed by EnVision FLEX substrate solution (Dakocytomation, Glostrup, Denmark) for $5 \mathrm{~min}$ at room temperature. Immunoreactivity was developed using 3,30- diaminobenzidine, for $5 \mathrm{~min}$ (DakoCytomation, Glostrup, Denmark), counterstained with Harris's hematoxylin and mounted. All rinses were performed three times in EnVision FLEX wash buffer.

Fifteen fields were evaluated, 5 from the furcation, 5 from the periodontal ligament and 5 from the alveolar bone, and the cells that presented a brownish coloration were considered positive. Negative controls were performed replacing the primaries antibodies for the same PBS/BSA solution. In each field, immunostained cells are counted and results were presented as number of immunolabeled cells per $\mu m^{2}$ of tissue.

\section{Statistical Analyses}

Non-paired student t-test and Mann-Whitney nonparametric test were used to determine significant differences between groups. The intraexaminer concordance was evaluated by paired t-test $10 \%$ of histological sections after 14 days of initial analysis. The significance level was always set at $p<0.05$, and all calculations were performed using GraphPad program Prism 5.0 (GraphPad Software Inc, La Jolla, CA, USA).

\section{Results}

\section{Histological Analysis}

Representative histological section of mandible in first molar region of Sham and CLP rats is demonstrated in figures 2 and 3, respectively. These figures also depict periodontal ligament, the alveolar bone and the furcation region in high magnification (Fig. 2B-D and Fig. 3B-D).

The collagen fibers $(p=0.7809)$, fibroblasts $(p=0.3741)$, blood vessels ( $p=0.1714)$, inflammatory cells $(p=0.9997)$, and blank spaces $(p=0.2921)$ were also similar in the periodontal ligament region in Sham and CLP rats (Fig. 4AE). In the alveolar bone, bone matrix ( $p=0.4892)$, osteocytes
( $p=0.5282)$, blood vessels $(p=0.1057)$ and inflammatory cells $(p=0.1739)$ were similar in Sham and CLP groups (Fig. $5 A-D)$. In the same way, bone matrix ( $p=0.6157)$, osteocytes ( $p=0.6213)$, blood vessels $(p=0.5781)$ and inflammatory cells $(p=0.1556)$ were similar in the furcation bone (Fig. $5 E-H)$.

\section{Immunohistochemical Analysis}

The number of BMP-2/4 labeled cells in the periodontal ligament region $(p=0.4848)$, alveolar bone $(p=0.4981)$ and the furcation area $(p=0.5887)$ was similar in Sham and CLP rats (Fig. 6A). In the same way, the RANKL immunolabeled cells levels (an essential mediator of bone resorption) was similar in periodontal ligament region $(p=0.6239)$, alveolar bone $(p=0.6991)$ and the furcation area $(p=0.9372)$ of Sham and CLP rats (Fig. 6B). Osteocalcin immunolabeled cells in the alveolar bone and the furcation area were similar in Sham and CLP rats. These immunostaining were observed diffusely in the bone matrix and did not allow quantitative evaluation. However, osteocalcin immunolabeled cells in periodontal ligament region was reduced $(p=0,0014)$ in CLP compared to Sham rats (Fig. 6C).

After 14 days, 10\% of measurements were repeated to access intra-examiner concordance (paired t-test). The results revealed a value of $p=0.1732$, representing absence of statistical difference.

\section{Discussion}

The present study demonstrated the effects of acute sepsis in the periodontal ligament, alveolar and furcation bone. Our findings did not demonstrate any histological modifications in periodontal ligament, alveolar and furcation bone after acute sepsis induction. However, an increase in the number of cells immunolabelled for osteocalcin was detected. Immunohistochemical analysis also showed no differences in BMP-2/4 and RANKL immunolabeling. These data suggest that sepsis did not result in pronounced effects on assessed tissues. However, the reduction in osteocalcin expression suggests the onset of deleterious effects of sepsis.

Our histological findings revealed absence of significant effects of sepsis in periodontal ligament, alveolar and furcation bone of mandibles. Histopathological features have been reported after acute sepsis induction in rats. However, these findings were detected in other organs, such as liver, kidney and lungs (14-16). After $24 \mathrm{~h}$, greater neutrophilic infiltration and interstitial edema were observed in the lungs of CLP rats (14). Other authors also reported the presence of histological alterations in the pulmonary tissue of rats only $2 \mathrm{~h}$ after the CLP procedure (15). Moreover, histological evaluation of the liver revealed the presence of inflammatory infiltrate, sinusoids dilation and necrosis areas (16). In this way, the absence 

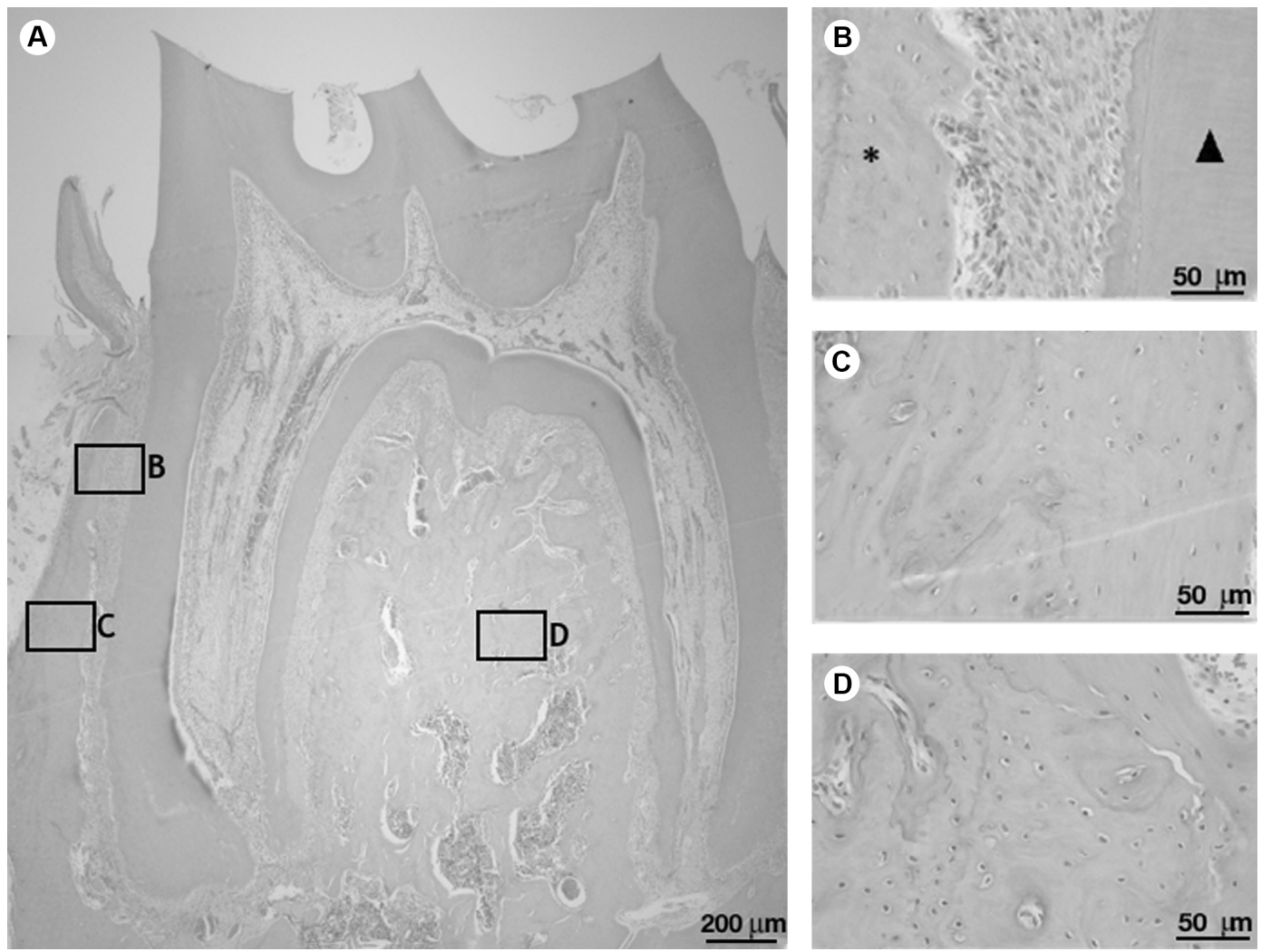

Figure 2. Histological findings of first molar of hemimandibles of Sham group (A). Observe the absence of histological changes in periodontal ligament (B), alveolar (C) and furcation bone (D). ( $\mathbf{\Delta})$ indicates root dentin and (*) indicates alveolar bone.
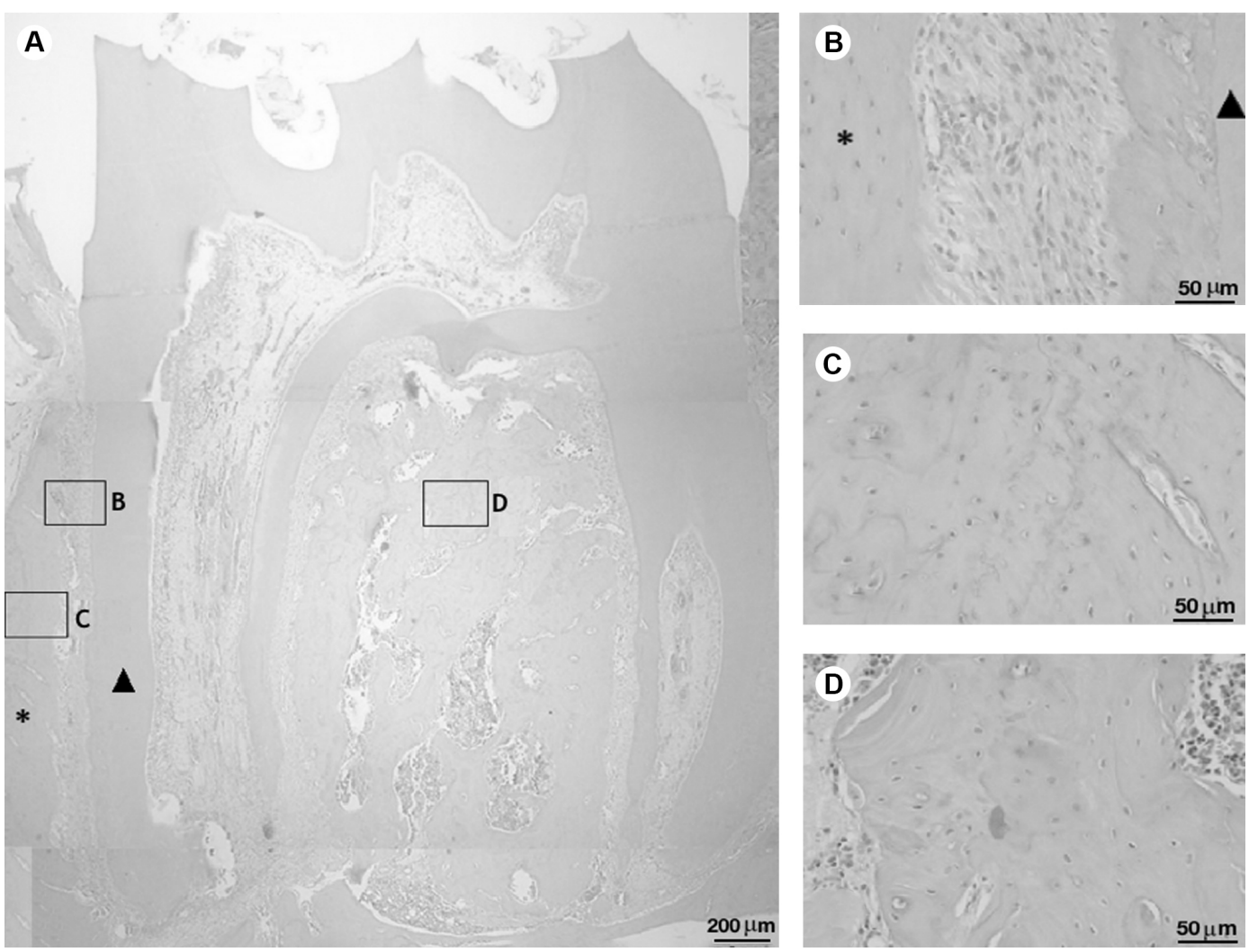

Figure 3. Histological findings of first molar of hemimandibles of CLP group (A). Observe the absence of histological changes in periodontal ligament (B), alveolar (C) and furcation bone (D). ( $\mathbf{\Delta})$ indicates root dentin and (*) indicates alveolar bone. 
of significant histological alterations in our experiments might be correlated to the time of sepsis evolution. Several studies have been associated systemic conditions and tissue alterations located in the same relevant microenvironment used longer experimental periods $(17,18)$.

In accordance, other authors have been described altered levels of inflammatory mediators in presence of acute sepsis. After 24 h, higher levels of IL-6, TNF- $\alpha$ and oxidative stress markers were observed in serum and pulmonary tissue samples of CLP rats compared to the control group (14). Increased IL-1 and TNF- $\alpha$ seric levels were also observed in rats after $24 \mathrm{~h}$ of sepsis induction (CLP model) (16).

Regarding to immunohistochemical analysis, our results did not detect differences between BMP-2/4and RANKL labeling in CLP and Sham group. RANKL is an osteoclast differentiating factor produced by osteoblastic cells and enhances osteoclast differentiation and bone resorption. Several proinflammatory cytokines such as TNF and IL-1 upregulate expression of RANKL (19). Some authors reported increased bone resorption in patients during the sepsis acute phase, with persistency of this condition for longer periods (20). In this way, an increased expression of genes involved in the osteoclast differentiation was observed in patients with septic shock (21). Like RANKL, bone morphogenetic proteins also act on bone metabolism, however they are implicated in osteogenesis (22). Our experiments showed no differences in the number of RANKL and BMP-2/4 immunolabeled cells, which suggests that earlier stages of sepsis might not alter the expression
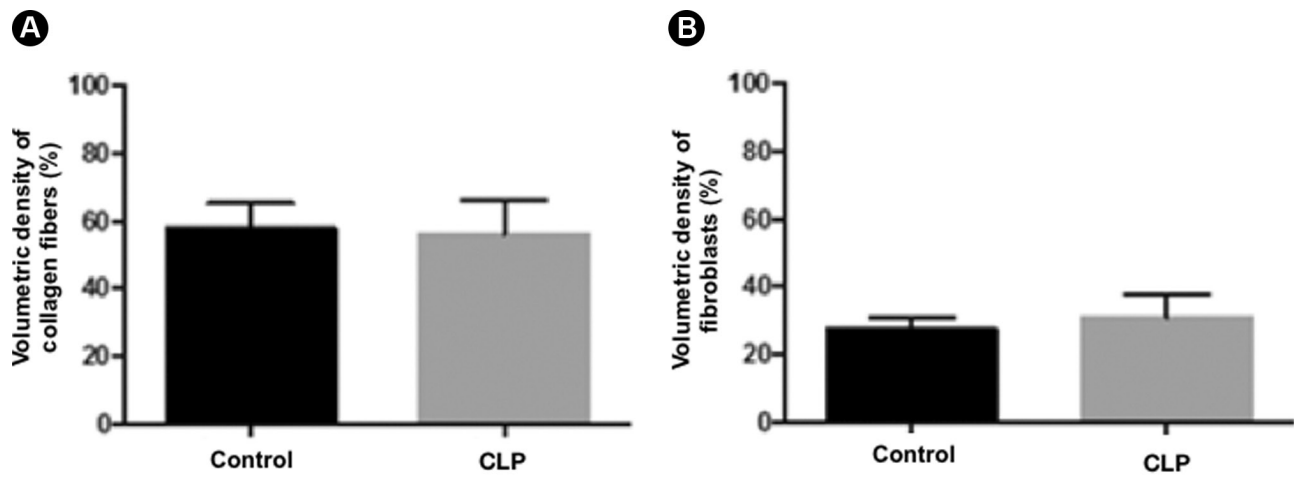

C

(D)
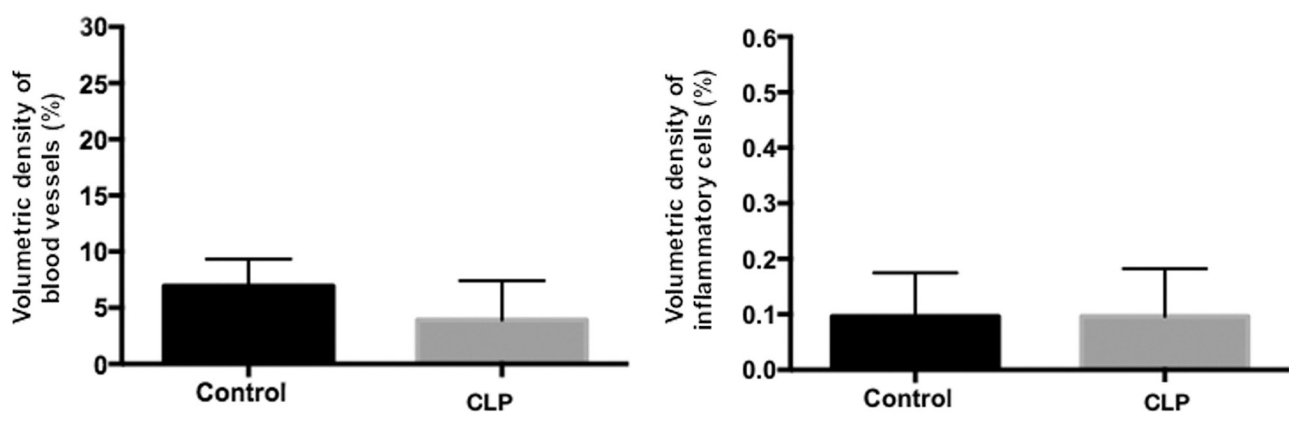

E

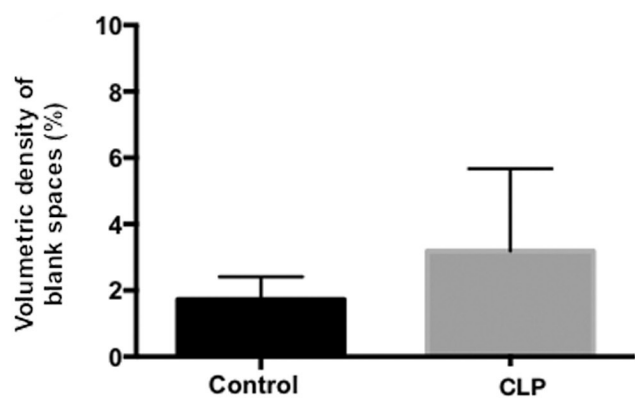

Figure 4. Volume density of collagenous fibers (A), fibroblasts (B), blood vessels (C), inflammatory cells (D), and blank spaces probably occupied by intercellular liquid and/or the inflammatory exudate (E) in the periodontal ligament. The results represent the mean and standard deviation values. Observe the absence of statical differences between groups 
of relevant bone mediators. However, reduced number of osteocalcin immunolabelled cells were detected in the CLP group.

Osteocalcin is the most abundant non-collagenous bone matrix protein, synthetized by osteoblasts and osteocytes. This protein has been described as a marker of osteoblastic activity and believed to regulate mineralization process (23). Besides the effects on the skeleton, non-skeletal effects have been related to osteocalcin such as angiogenesis, male reproduction and energy metabolism (24).

In the context of inflammatory and infectious diseases, it was demonstrated that the induction of an infectious scenario by LPS inoculation resulted in a progressive reduction in the expression of osteocalcin after $6,12,24$ and $72 \mathrm{~h}$ (24). These results are in accordance with our findings, suggesting the putative suppression of osteogenesis,
A

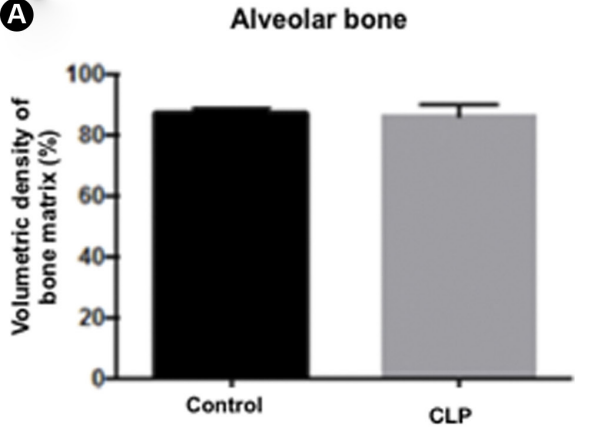

B

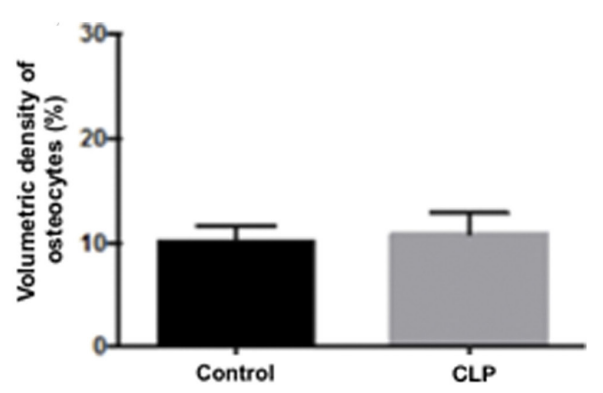

E

Furcation bone area

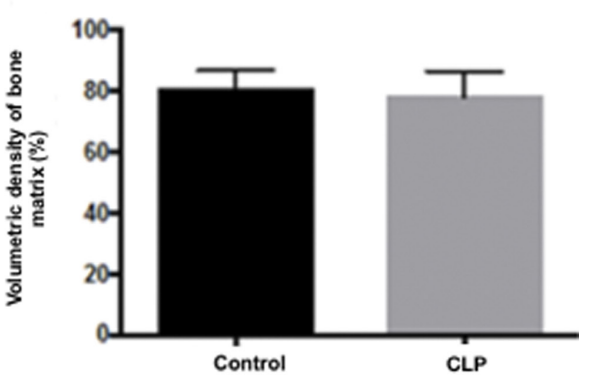

F

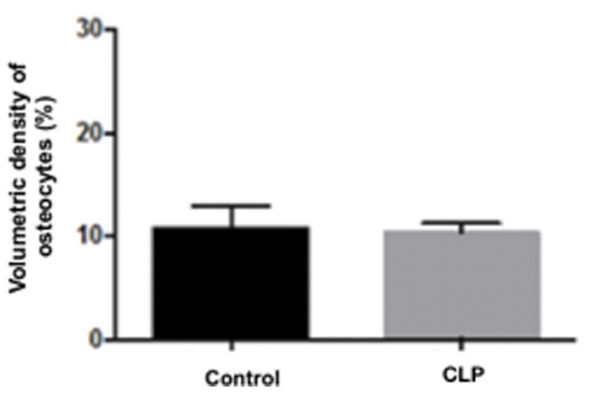

C

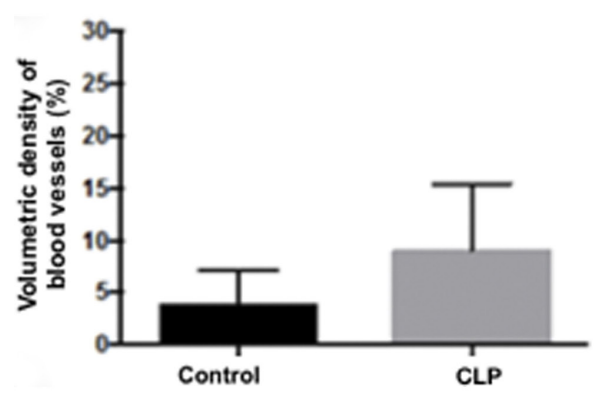

G
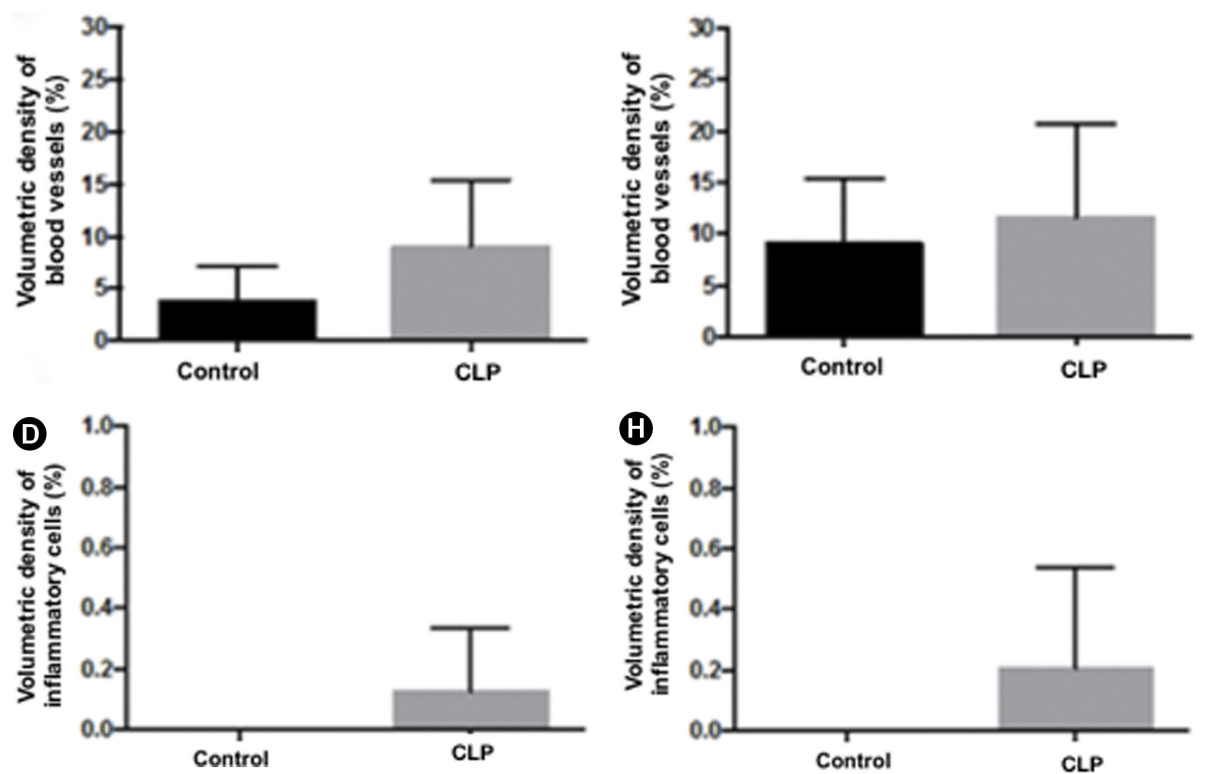

Figure 5. Volume density of the bone matrix, osteocytes, blood vessels, and inflammatory cells of alveolar (A-D) and furcation (E-H) bone tissue. The results represent the mean and standard deviation values. Observe the absence of statical differences between groups. 
exemplified by the reduction of osteocalcin expression, in presence of inflammatory diseases such as sepsis (24).

Also, in our study, osteocalcin labeling in the alveolar bone and the furcation area occurred homogeneously and were not considered regarding the number of immunolabeled cells. In fact, osteocalcin is the most abounding non-collagenous protein in the bone matrix, unlike the BMP-2/4 and RANKL labeling, which are visualized more locally $(25,26)$.

These results might be related to its important role in the mineralization, which is inversely associated to the presence of inflammatory markers which contribute to the bone resorption (27). Therefore, sepsis has been associated to increased expression of pro-inflammatory mediators. The effect of this increase in the bone metabolism has been widely discussed and demonstrates deleterious impact on different biological systems. In fact, sepsis induction resulted in increased NO formation, higher and persistent levels of IL-6, IL-1 $\beta$ and TNF- $\alpha$ (28), associated to reduction levels of osteocalcin and CBFA-1 (29). Recent studies have been suggested IL-17, IL-27, and IL-33 as a novel cytokine axis during sepsis (30). IL-17 primarily acts
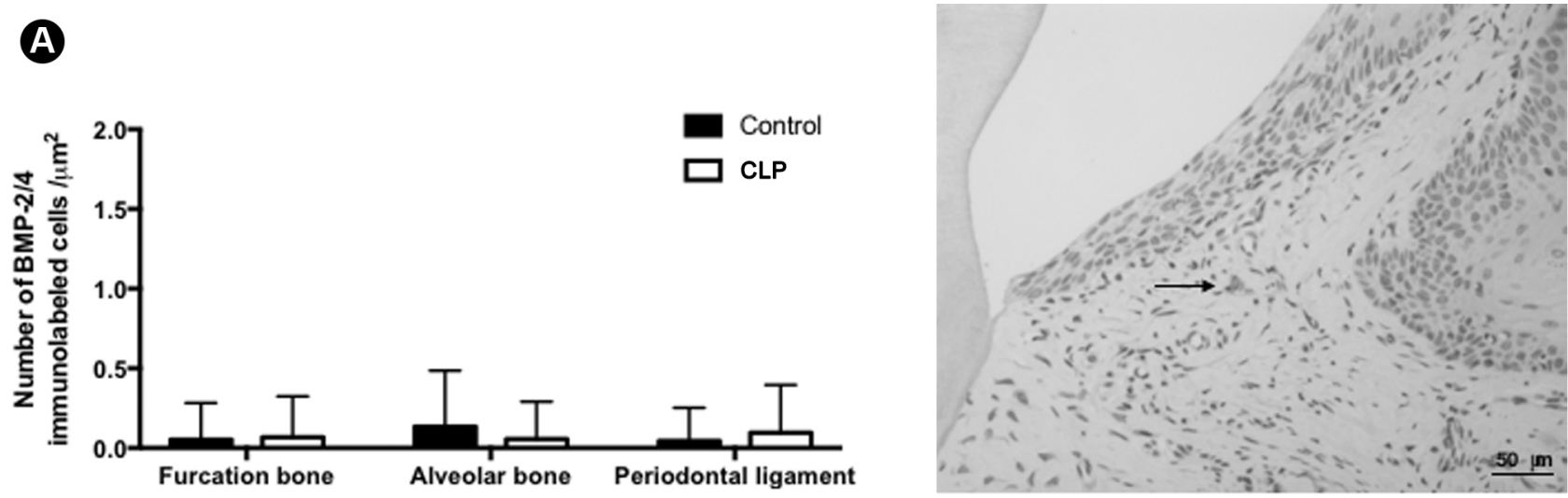

B
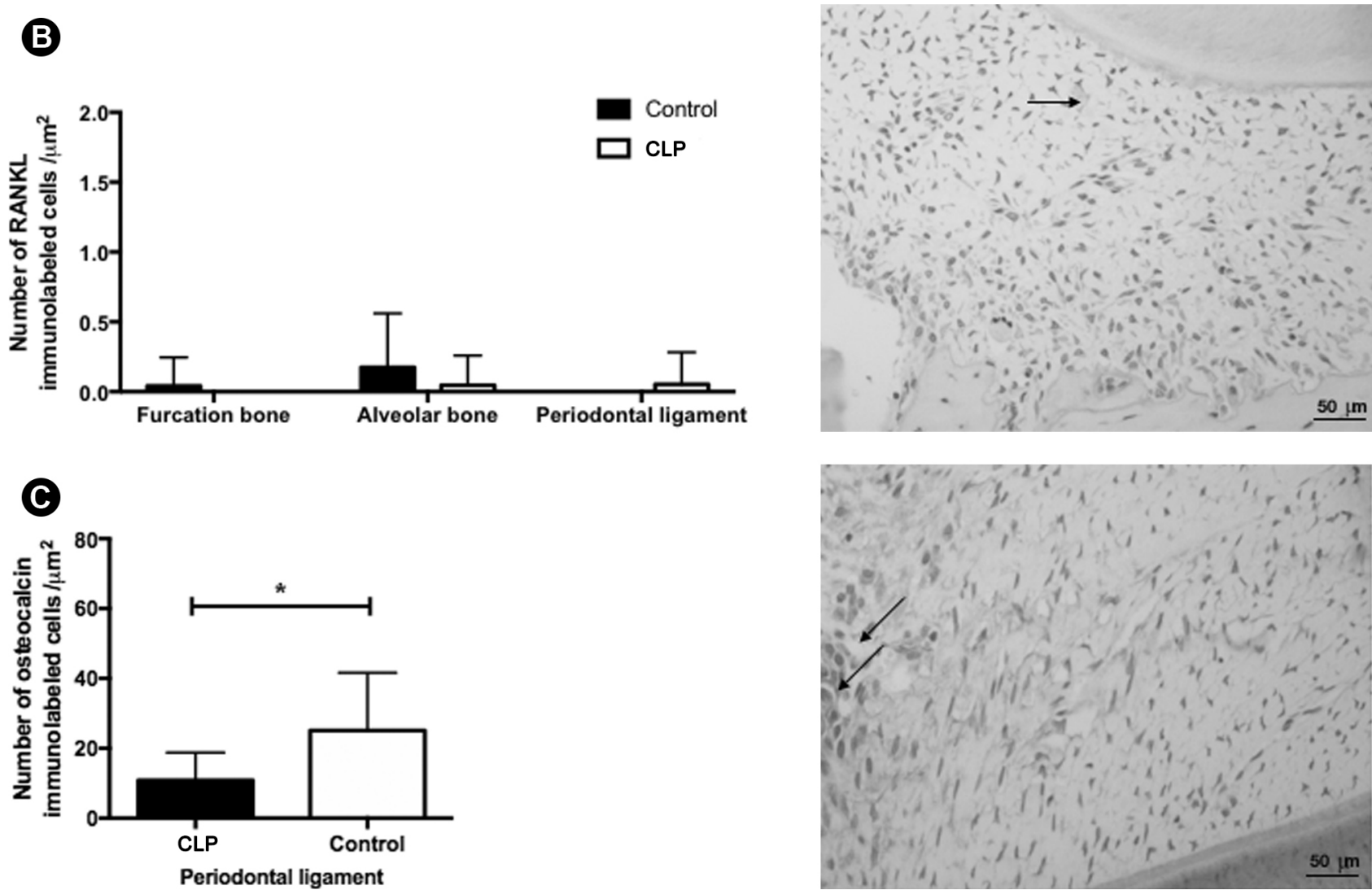

Figure 6. BMP-2/4 (A), RANKL (B), and osteocalcin (C) immunolabeling of the periodontal ligament, alveolar bone and the furcation bone regions. The results represent the mean and standard deviation values. Narrows indicated the presence of labelled cells. Mann-Whitney non-parametric test, ${ }^{*}$ p $<0.05$ compared to Sham group. 
to promote the inflammatory response in mucosal tissue while IL-33 modulates Th2 responses and decreases the differentiation of T cells into Th17 cells. In addition, IL27 has been associated to inhibition of Th17 cells $(30,31)$. In this context, other cytokines such as IL-7 have been approached as possible sepsis treatment strategies, since it is important for the maintenance of lymphocytes and can accelerate the reconstitution of effector lymphocytes in sepsis (32).

Taken together, these findings demonstrate the relevant influence of sepsis in the regulation of inflammatory and immune mediators, which regulate different biological systems. In this way, our results revealed the putative influence of sepsis in the bone metabolism, even in absence of histological changes. Interestingly, and in accordance with our findings, altered biomechanical properties of bone were detected within $24 \mathrm{~h}$ in a rodent sepsis model (CLP model) (33). Thus, early stages of sepsis may result in more discrete changes, possibly followed by the establishment of histopathological findings. In fact, further studies should be performed to evaluate the putative role of other mediators involved in inflammatory response and bone metabolism such as RANK/RANKL/OPG triad, TNF-alpha, IL-1 beta, IL-7, IL-17, IL-33, which is one of the limitations of study. Moreover, it would be interesting to evaluate these possible changes in the after induction and establishment of periodontal disease, allowing to access the influence of sepsis on previously installed infectious conditions.

These data can contribute to the development of more effective preventive and therapeutic strategies with the oral health care of patients with sepsis. In conclusion, the acute sepsis induction resulted in reduced number of osteocalcin immunolabelled cells only in periodontal ligament region. Moreover, no significant histological differences were observed in the periodontium of rats after $24 \mathrm{~h}$ of sepsis induction. Bearing in mind the role of osteocalcin in bone remodeling, the present study contributes to revealing that in-hospital septic patients need meticulously periodontal analysis and dental implant surgery can result in higher failure rates in patients with sepsis.

\section{Resumo}

0 objetivo deste estudo foi avaliar o efeito da sepse aguda no ligamento periodontal, osso alveolar e osso da furca por meio de análise histológica e imunohistoquimica. 0 modelo de sepse em ratos foi estabelecido pelo procedimento de ligação e perfuração do ceco (CLP). Doze ratos foram divididos de forma randomizada em ratos sépticos $(n=6)$ e controle grupo Sham $(n=6)$. Os animais foram eutanasiados após 24 horas e suas hemimandibulas foram submetidas aos procedimentos histotécnicos para análise histomorfométricos (matriz óssea, fibras colágenas, fibroblastos, osteócitos, células inflamatórias e vasos sanguíneos) e imunohistoquímicos (BMP-2/4, RANKL e osteocalcina) no osso alveolar, osso de furca e ligamento periodontal. Nossos resultados demonstraram que os parâmetros histomorfométricos foram similares no osso alveolar, osso de furca e ligamento periodontal dos animais do grupo sepse e do grupo
Sham. Em relação à análise por imunohistoquímica, o número de células imunomarcadas para BMP-2/4 e RANKL também foi similar em ambos os grupos. Entretanto, houve redução $(\mathrm{p}=0.0014)$ no número de células imunomarcadas para osteocalcina no ligamento periodontal de ratos sépticos em relação ao grupo Sham. Como conclusão, o estabelecimento de sepse aguda resultou em um número reduzido de células imunomarcadas para osteocalcina na região do ligamento periodontal $(p=0,0014)$. Além disso, não foram observadas diferenças histológicas significativas no periodonto de ratos na presença de sepse aguda. Considerando o papel da osteocalcina na remodelação óssea, este estudo contribui para revelar a importância da avaliação periodontal cuidadosa na presença de sepse.

\section{Acknowledgments}

This research was supported by a grant from $\mathrm{CNPq}$, CAPES, Federal University of Uberlandia and FAPEMIG. Our best regards to National Institute of Science and Technology in Theranostics and Nanobiotechnology (CNPq Process N.:465669/2014-0) and to Rodent Vivarium Network (REBIR-UFU).

\section{References}

1. Shankar-Hari M, Philips GS, Levy ML, Seymour CW, Liu VX, Deutschman $\mathrm{CS}$, et al. Developing a new definition and assessing new clinical criteria for septic shock: for the third international consensus definitions for sepsis and septic shock (sepsis-3). JAMA 2016;315:775-787.

2. Fleischmann $C$, Scherag A, Adhikari NK, Hartog CS, Tsaganos T, Schlattmann $\mathrm{P}$, et al. Assessment of global incidence and mortality of hospital-treated sepsis. Current estimates and limitations. Am J Respir Crit Care Med 2016;193:259-272.

3. Reinhart K, Daniels R, Kisson N, Machado FR, Schachter RD, Finfer S. Recognizing sepsis as a global health priority - a who resolution. $N$ Engl J Med 2017;377:414-417.

4. Nedeva C, Menassa J, Puthalakath H.Sepsis: Inflammation is a necessary evil. Front Cell Dev Biol 2019;20;7:108.

5. Chousterman BG, Swirski FK, Weber GF. Cytokine storm and sepsis disease pathogenesis. Semin Immunopathol 2017;39:517-528.

6. Mera S, Tatulescu D, Cismaru C, Bondor C, Slavcovici A, Zanc $\mathrm{V}$, et al. Multiplex cytokine profiling in patients with sepsis. APMIS 2011;119:155-163.

7. Cardoso-Sousa L, Aguiar EMG, Caixeta DC, Vilela DD, Costa DPD, Silva $\mathrm{TL}_{\text {, et }}$ al. Effects of salbutamol and phlorizin on acute pulmonary inflammation and disease severity in experimental sepsis. PLoS One. 2019 Sep 19;14:e0222575.

8. Tu H, Lai X, Li J, Huang L, Liu Y, Cao J. Interleukin-26 is overexpressed in human sepsis and contributes to inflammation, organ injury, and mortality in murine sepsis. Crit Care. 2019; 29;23:290.

9. Claudino M, Gennaro G, Cestari TM, Spadella CT, Garlet GP, Assis GF. Spontaneous periodontitis development in diabetic rats involves an unrestricted expression of inflammatory cytokines and tissue destructive factors in the absence of major changes in commensal oral microbiota. Exp Diabetes Res 2012;12:356841.

10. Claudino M, Ceolin DS, Alberti S, Cestari TM, Spadella CT, RubiraBullen IR, et al. Alloxan-induced diabetes triggers the development of periodontal disease in rats. Plos One 2007;2:1320.

11. Fujita $Y$, Maki K. High-fat diet-induced obesity triggers alveolar bone loss and spontaneous periodontal disease in growing mice. BMC Obes 2016;3:1.

12. Cavagni J, Wagner TP, Gaio EJ, Rego RO, Torres IL, Rosing CK. Obesity may increase the occurrence of spontaneous periodontal disease in Wistar rats. Arch Oral Biol 2013;58:1034-1039.

13. Terashima A, Okamoto K, Nakashima T, Akira S, Ikuta K, Takayanagui $H$. Sepsis-induced osteoblast ablation causes immunodeficiency. Immunity 2016;44:1434-1443.

14. Demir M, Taylan M, Kaya H, Ekinci A, Arslan D, Aslan E, et al. Histopathological and biochemical effects of ecballium elaterium on sepsis-induced lung injury. J Invest Surg 2016;29:302-308.

15. Gill SE, Rohan M, Mehta S. Role of pulmonary microvascular endothelial cell apoptosis in murine sepsis-induced lung injury in vivo. 
Respir Res 2015;16:109.

16. Arslan MS, Basuguy E, Ibiloglu I, Bozdemir E, Zuytun H, Sahin A, et al. Effects of ecballium elaterium on proinflammatory cytokines in a rat model of sepsis. J Invest Surg 2016;29:399-404.

17. Claudino M, Nunes IS, Gennaro G, Cestari TM, Spadella CT, Garlet $\mathrm{GP}$, et al. Diabetes triggers the loss of tooth structure associated to radiographical and histological dental changes and its evolution to progressive pulp and periapical lesions in rats. Arch Oral Biol 2015;60:1690-1698.

18. Liu Z, Liu L, Kang C, Xie Q, Zhang B, Li Y. Effects of estrogen deficiency on microstructural changes in rat alveolar bone proper and periodontal ligament. Mol Med Rep 2015;12:3508-3514.

19. Fardellone P, Sejourne A, Paccou J, Goeb V. Bone remodelling markers in rheumatoid arthritis. Mediators Inflamm 2014;2014:484280.

20. Smith LM, Ccthbertson B, Harvie J, Webster N, Robins S, Ralson SH. Increased bone resorption in the critically ill: Association with sepsis and increased nitric oxide production. Crit Care Med 2002;30:837-840.

21. Mukhopadhyay $S$, Thatoi PK, Pandey AD, Das BK, Ravindran $B$, Bhattacharjee $S$, et al. Transcriptomic meta-analysis reveals upregulation of gene expression functional in osteoclast differentiation in human septic shock. Plos One 2017;12:e0171689.

22. Salazar VS, Gamer LW, Rosen V. BMP signalling in skeletal development, disease and repair. Nat Rev Endocrinol 2016;12:203-221.

23. Bailey S, Karsenty G, Gundenberg C, Vashishth D. Osteocalcin and osteopontin influence bone morphology and mechanical properties. Ann N Y Acad Sci 2017;1409:79-84.

24. Yang J, Su N, Du X, Chen L. Gene expression patterns in bone following lipopolysaccharide stimulation. Cell Mol Biol Lett 2014;19:611-622.

25. Zoricic S, Maric I, Bobinac D, Vukicevic S. Expression of bone morphogenetic proteins and cartilage-derived morphogenetic proteins during osteophyte formation in humans. J Anat 2003;202:269-277.
26. Moraes M, Lucena HF, Azevedo PR, Queiroz LM, Costa L. Comparative immunohistochemical expression of RANK, RANKL and OPG in radicular and dentigerous cysts. Arch Oral Biol 2011;56:1256-1263.

27. Garlet GP. Destructive and protective roles of cytokines in periodontitis: a re-appraisal from host defense and tissue destruction viewpoints. J Dent Res 2010;89:1349-1363.

28. Restagno D, Venet $F$, Paquet $C$, Freyburger $L$, Allaouchiche $B$, Monneret $\mathrm{G}$, et al. mice survival and plasmatic cytokine secretion in a "two hit" model of sepsis depend on intratracheal pseudomonas aeruginosa bacterial load. PLoS One 2016;11:1-19.

29. Yang J, Su N, Du X, Chen L. Gene expression patterns in bone following Lipopolysaccharide stimulation. Cell Mol Biol Lett 2014;19:611-622.

30. Morrow KN, Coopersmith CM, Ford ML. IL-17, IL-27, and IL-33: A novel axis linked to immunological dysfunction during sepsis. front immunol. 2019;22;10:1982.

31. Lv R, Zhao J, Lei M, Xiao D, Yu Y, Xie J. IL-33 Attenuates sepsis by inhibiting IL-17 receptor signaling through upregulation of SOCS3. Cell Physiol Biochem. 2017;42:1961-1972.

32. Kulkarni U, Herrmenau C, Win SJ, Bauer M, Kamradt T. IL-7 treatment augments and prolongs sepsis-induced expansion of IL-10producing B lymphocytes and myeloid-derived suppressor cells. PLoS One. 2018;21;13:e0192304.

33. Puthucheary ZA, Sun Y, Zeng K, Vu LH, Zhang ZW, Lim RZL, et al. Sepsis reduces bone strength before morphologic changes are identifiable. Crit Care Med 2017;45:1254-1261.

Received July 4, 2019 Accepted December 11, 2019 